\title{
Antioxidant Capacity of Venezuelan Honey in Wistar Rat Homogenates
}

\author{
Elizabeth Pérez, ${ }^{1}$ Antonio J. Rodríguez-Malaver, ${ }^{1}$ and Patricia $\mathrm{Vit}^{2}$ \\ ${ }^{1}$ Laboratorio de Bioquímica Adaptativa, Departamento de Bioquímica, Facultad de Medicina; and \\ ${ }^{2}$ Apiterapia y Bioquímica Antioxidante, Departamento de Ciencia de Los Alimentos, Facultad de Farmacia y \\ Bioanálisis, Universidad de Los Andes, Mérida, Mérida, Venezuela
}

\begin{abstract}
The antioxidant effect of several polyphenolic compounds is well known. However, little is known about the antioxidant capacity of Venezuelan honey, which has a high content of polyphenolic compounds. In this work, the antioxidant capacity of a genuine honey produced in Mérida, Venezuela was studied using the ferrous iron oxidation with xylenol orange method, the thiobarbituric acid method, and the determination of antioxidant activity. We found that this honey has the capacity to decrease significantly the concentration of lipid hydroperoxides and malondialdehyde, produced during the lipid peroxidation process, in a comparable way with other widely studied antioxidants such as melatonin and vitamin E. It was found that the antioxidant activity in the $50 \%$ honey dilution, the highest concentration we tested, was equivalent to a concentration of uric acid of $0.62 \mathrm{mM}$.
\end{abstract}

KEY WORDS: • antioxidant activity • Fenton's reagent • honey • lipid hydroperoxides • malondialdehyde

\section{INTRODUCTION}

$\mathbf{H}$ ONEY IS A REMARKABLE PRODUCT from the hive prepared by honeybees from the nectar and other sugary substances derived from many plants. ${ }^{1}$ All over the world, honey is considered a part of traditional medicine. ${ }^{2-4}$ However, it has so far been neglected as a therapeutic agent in modern medicine because of the lack of systematic scientific studies in support of its medical attributes. Currently, scientific support has begun to emerge with several publications on the diversity of its therapeutic effectiveness. ${ }^{5}$ Moreover, honey has been reported to be effective in the healing of wounds and burns ${ }^{6,7}$ and as an antimicrobial agent ${ }^{4-9}$ and in providing gastric protection against acute and chronic gastric lesions. ${ }^{10,11}$

Currently, there is overwhelming evidence that free radicals cause oxidative damage to lipids, proteins, and nucleic acids, leading to many biological complications including carcinogenesis, mutagenesis, aging, and atherosclerosis. ${ }^{12}$ In general, the term "antioxidant" refers to any substance that when present at low concentrations compared with those of an oxidizable substrate significantly delays or prevents oxidation of that substrate, including various types of molecules found in vivo. ${ }^{13}$ Natural antioxidants can be phenolic compounds (tocopherol, flavonoids, and phenolic acids),

Manuscript received July 6, 2005. Revision accepted October 12, 2005.

Address reprint requests to: Dr. Antonio J. Rodríguez-Malaver, Laboratorio de Bioquímica Adaptativa, Departamento de Bioquímica, Facultad de Medicina, Universidad de Los Andes, Mérida, Mérida 5101, Venezuela,E-mail: antoniorod@cantv.net nitrogen compounds (alkaloids, chlorophyll derivatives, amino acids, and amines), or carotenoids as well as ascorbic acid. ${ }^{14-16}$

A study done by Al-Mamary et al. ${ }^{17}$ has demonstrated that several types of honey from different countries have an antioxidant capacity that was dependent on the concentration of phenolic groups. Other studies were performed to assay the antioxidant capacity of honey. ${ }^{18-21}$

The antioxidant capacity of honey from Venezuela was assayed for lipid peroxidation. This process consists of the oxidation of membrane lipids through autooxidative reactions that result in the formation of lipid hydroperoxides and malondialdehyde (MDA). ${ }^{22,23}$ Peroxidation can change membrane fluidity and affect several cell functions such as ion permeability and ATPase activity. ${ }^{24,25}$

Because of the large variety of pathologies that have been related to reactive oxygen species (ROS), it is quite important to find new antioxidants that could inhibit or prevent the effects of ROS. Therefore, the aim of this work was to evaluate the effect of a genuine honey from Mérida, Venezuela, on lipid peroxidation and to compare its antioxidant activity with that of melatonin, vitamin $\mathrm{E}$, and uric acid.

\section{MATERIALS AND METHODS}

\section{Chemicals}

Methanol [high performance liquid chromatography (HPLC) grade], sulfuric acid, hydrogen peroxide, NADH, acetic acid, thiobarbituric acid (TBA), sodium dodecyl sul- 
fate (SDS), 1,1,3,3-tetramethoxypropane (TMP), xylenol orange, EDTA, and uric acid were purchased from Sigma Chemical Co. (St. Louis, MO). Copper (II) sulfate, manganese (II) chloride tetrahydrate, iron chloride, sodium benzoate, sodium hydroxide, trichloroacetic acid, sodium carbonate, sodium and potassium tartrate, Folin-Ciocalteu's phenol reagent, and butylhydroxytoluene (BHT) were purchased from Merck (Darmstadt, Germany). Milli- ${ }^{\circledR}$ plus water (Millipore, Bedford, MA) was used for all preparations.

\section{Honey samples}

Honey was purchased at the local market in Mérida from SRI Nitay, and diluted with ultrapure water at 1:2 and 1:4 dilutions.

\section{Rat homogenates}

Rats were handled according international regulations, and maintained under regular conditions of humidity, food, circadian cycles, and temperature. Kidney, brain, liver, and lung homogenates were obtained from 3-month-old male Wistar rats weighing 200-250 g. For the ferrous ion oxidation with xylenol orange (FOX) method, $40 \%$ (wt/vol) homogenates were prepared in HPLC-grade methanol. For the TBA method, 3.3\% (wt/vol) homogenates were prepared in $50 \mathrm{~m} M$ phosphate buffer ( $\mathrm{pH}$ 7.4).

\section{FOX method}

Lipid peroxidation was conducted for a 60-minute interval at $37^{\circ} \mathrm{C}$. The mixture for lipid hydroperoxide generation contained $10 \mu \mathrm{L}$ of Fenton's reagent 1 ( $5 \mu \mathrm{L}$ of $5 \mathrm{mM}$ manganese chloride and $5 \mu \mathrm{L}$ of $50 \mathrm{~m} M$ hydrogen peroxide), 10 $\mu \mathrm{L}$ of the aqueous extract, and $80 \mu \mathrm{L}$ of each homogenate. ${ }^{26}$ Nine hundred microliters of FOX reagent ( $49 \mathrm{mg}$ of ferrous

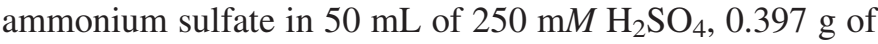
BHT, and $0.038 \mathrm{~g}$ of xylenol orange in $950 \mathrm{~mL}$ of HPLCgrade methanol) was added to each sample and left to react for 30 minutes at room temperature. The absorbance was read at $560 \mathrm{~nm}$. Hydrogen peroxide was used as a standard.

\section{Enzymatic and nonenzymatic lipid peroxidation}

Lipid peroxidation was conducted for a 60 -minute interval at $37^{\circ} \mathrm{C}$ in a mixture that contained $100 \mu \mathrm{L}$ of aqueous extract, $50 \mu \mathrm{L}$ of $5 \mathrm{~m} M$ iron chloride, $50 \mu \mathrm{L}$ of $50 \mathrm{~m} M$ hydrogen peroxide (Fenton's reagent $\mathbf{2}$, for nonenzymatic lipid peroxidation) or $100 \mu \mathrm{L}$ of $2 \mathrm{mM} \mathrm{NADH}$ (for enzymatic lipid peroxidation), and $400 \mu \mathrm{L}$ of each homogenate at 3.3\% (wt/vol). ${ }^{27}$ The mixture was diluted with $600 \mu \mathrm{L}$ of Milli$\mathrm{Q}$ water. The following reagents were added to $500 \mu \mathrm{L}$ of this mixture: $1.5 \mathrm{~mL}$ of $20 \%$ acetic acid $(\mathrm{pH} 3.5), 1.2 \mathrm{~mL}$ of $1 \%$ TBA, $10 \mu \mathrm{L}$ of $10 \mathrm{mM}$ BHT, and $0.2 \mathrm{~mL}$ of $10 \%$ SDS. The mixture was left to react for 1 hour at $100^{\circ} \mathrm{C}$ and was centrifuged at 2,000 rpm for 10 minutes in a $\mathrm{BHG}$ (Gosheim, Germany) Optima centrifuge. The absorbance was measured at $532 \mathrm{~nm}$. TMP was used as a standard.

\section{Antioxidant activity (AOA) method}

The AOA was determined using the method developed by Koracevic et al. ${ }^{28}$ In this method a standardized solution of Fe-EDTA complex reacts with hydrogen peroxide by a Fenton-type reaction, leading to the formation of hydroxyl radicals. These radicals degraded benzoate, resulting in the formation of TBA-reactive substances (TBARS). This reaction was monitored spectrophotometrically, and the inhibition of color development was defined as the AOA.

\section{Measurement of phenolic group concentration}

The determination of phenolic group concentration was carried out by a colorimetric technique based on the FolinCiocalteu's phenol reagent. A volume of $100 \mu \mathrm{L}$ of aqueous extract was completed up to $500 \mu \mathrm{L}$ with water, and was mixed with $1.5 \mathrm{~mL}$ of solution $\mathrm{C}\{25 \mathrm{~mL}$ of solution A [1\% (wt/vol) SDS, 0.4\% (wt/vol) $\mathrm{NaOH}, 2 \%(\mathrm{wt} / \mathrm{vol})$ sodium carbonate, and $0.16 \%(\mathrm{wt} / \mathrm{vol})$ sodium and potassium tartrate] with $250 \mu \mathrm{L}$ of $4 \%$ (wt/vol) $\mathrm{CuSO}_{4}$. The samples were placed in a water bath at $37^{\circ} \mathrm{C}$ for 10 minutes. Then, $150 \mu \mathrm{L}$ of Folin-Ciocalteu's phenol reagent diluted 1:2 was added to the reaction mixture, and incubation was continued for 10 minutes. Absorbance was recorded at 750 $\mathrm{nm}$, and phenol was used as a standard.

Table 1. Percentage of Lipid Peroxidation Using Three Different Inducers in Different Tissues

\begin{tabular}{lccc}
\hline & & Lipid peroxidation induction (\%) \\
\cline { 2 - 4 } Organ & $\begin{array}{c}\text { FOX method } \\
\text { (Fenton's reagent 1) }\end{array}$ & $\begin{array}{c}\text { Nonenzymatic TBA method } \\
\text { (Fenton's reagent 2) }\end{array}$ & $\begin{array}{c}\text { Enzymatic TBA method } \\
(\text { NADH) }\end{array}$ \\
\hline Kidney & $80 \pm 1^{\mathrm{a}}$ & $81 \pm 1^{\mathrm{a}}$ & $78 \pm 1^{\mathrm{a}}$ \\
Brain & $85 \pm 1^{\mathrm{a}}$ & $84 \pm 1^{\mathrm{a}}$ & $82 \pm 2^{\mathrm{a}}$ \\
Lung & $81 \pm 2^{\mathrm{a}}$ & $74 \pm 1^{\mathrm{a}}$ & $78 \pm 1^{\mathrm{a}}$ \\
Liver & $79 \pm 2^{\mathrm{a}}$ & $76 \pm 1^{\mathrm{a}}$ & $77 \pm 1^{\mathrm{a}}$ \\
\hline
\end{tabular}

Data are mean \pm SE $(n=3)$. Means within a column sharing the same letter are not significantly different by Newman-Keuls multiple comparison test $(P<.05)$. 


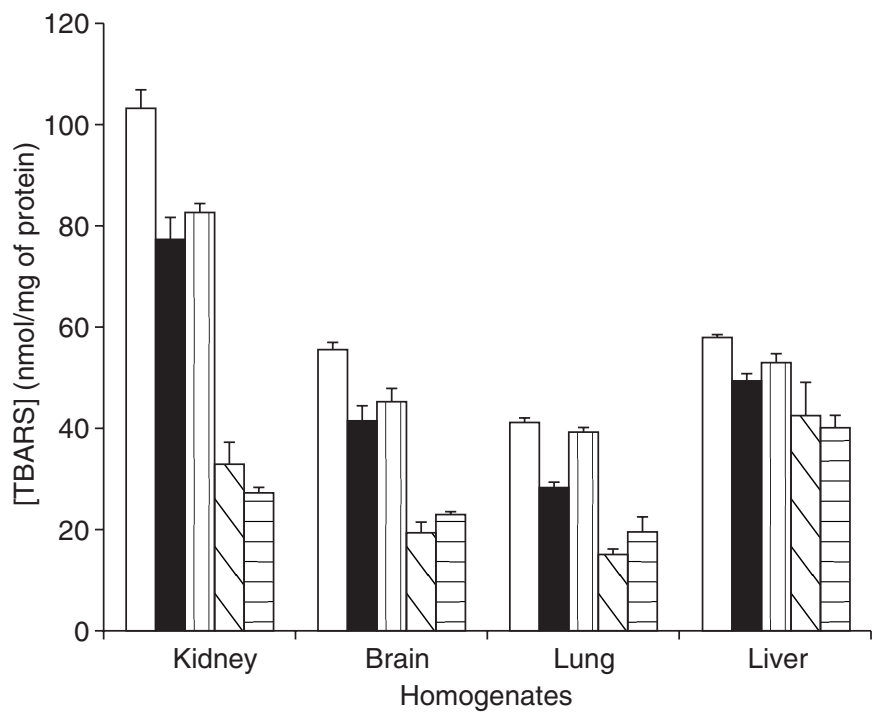

FIG. 1. Effect of different honey dilutions, vitamin E, and melatonin on TBARS content generated by Fenton's reagent 2 in the nonenzymatic TBA method assayed for 60 minutes at $37^{\circ} \mathrm{C}$ and homogenates at $3.3 \%(\mathrm{wt} / \mathrm{vol})$ in $50 \mathrm{mM}$ phosphate buffer ( $\mathrm{pH} 7.4)$ : homogenates in the presence of Fenton's reagent $2\left(50 \mathrm{~m} M \mathrm{H}_{2} \mathrm{O}_{2}\right.$ and $\left.5 \mathrm{mM} \mathrm{FeCl}\right)$ $(\square)$; homogenates in the presence of Fenton's reagent $\mathbf{2}$ and honey diluted 1:2 (ם); homogenates in the presence of Fenton's reagent $\mathbf{2}$ and honey diluted 1:4 $(\mathbb{\nabla})$; homogenates in the presence of Fenton's reagent 2 and melatonin at $1 \mu M($ 目); homogenates in the presence of Fenton's reagent 2 and vitamin $\mathrm{E}$ at $1 \mu M$.

\section{Measurement of protein concentration}

Protein concentrations were determined spectrophotometrically at $750 \mathrm{~nm}$ by the method of Lowry et al. ${ }^{29}$ with bovine serum albumin as the standard.

\section{Statistics}

All experiments were done in triplicate. Data were analyzed using a one-way analysis of variance and NewmanKeuls multiple comparison test $\left(\mathrm{Prism}^{\circledR}\right.$, Graph Pad, San Diego, CA).

\section{RESULTS}

\section{Effect of honey dilutions on lipid peroxidation}

First of all, we determined whether or not lipid peroxidation could be induced under our experimental conditions in a sufficient quantity to be able to quantify the antioxidant effect of our honey samples on this process. We used three different lipid peroxidation inducers: Fenton's reagent $\mathbf{1}$ $\left[\mathrm{H}_{2} \mathrm{O}_{2}+\mathrm{Mn}\right.$ (this ion was used because xylenol orange binds $\mathrm{Fe}$ in the FOX method)], Fenton's reagent $2\left(\mathrm{H}_{2} \mathrm{O}_{2}+\right.$ $\mathrm{Fe}$ ), and lipid peroxidation induced by NADH. It was found that lipid peroxidation was stimulated up to $85 \pm 1 \%$ with Fenton's reagent 1, up to $84 \pm 1 \%$ with Fenton's reagent 2, and up to $82 \pm 2 \%$ with NADH (Table 1). These high percentages of lipid peroxidation allow us to readily establish the antioxidant effect of honey samples.

The results obtained by using nonenzymatic TBARS method are showed in Figure 1. It can be seen that the two dilutions of honey can reduce the content of TBARS generated by a chemical mechanism in all the homogenates. Vitamin $\mathrm{E}$ and melatonin caused a further reduction in TBARS values. In comparison with other homogenates, there seems to be a higher reduction of TBARS content in the kidney homogenate for honey samples, and for vitamin E and melatonin. On the other hand, in the lung homogenate, a higher dilution has a lower antioxidant capacity, indicating that the antioxidant capacity of honey might be dependent on its concentration at least in this homogenate (Fig. 1).

When we studied the effect of honey samples on enzymatic lipid peroxidation, it was found that the less diluted honey samples were more effective than vitamin E and melatonin in both kidney and brain homogenates (Fig. 2). In contrast, in lung and liver homogenates, vitamin E and melatonin were more active than honey samples, with again the less diluted honey sample being more efficient than the most diluted in all cases (Fig. 2). In Figure 3 it is shown that both diluted honey samples and vitamin $\mathrm{E}$ and melatonin reduced the amounts of lipid hydroperoxides generated by Fenton's

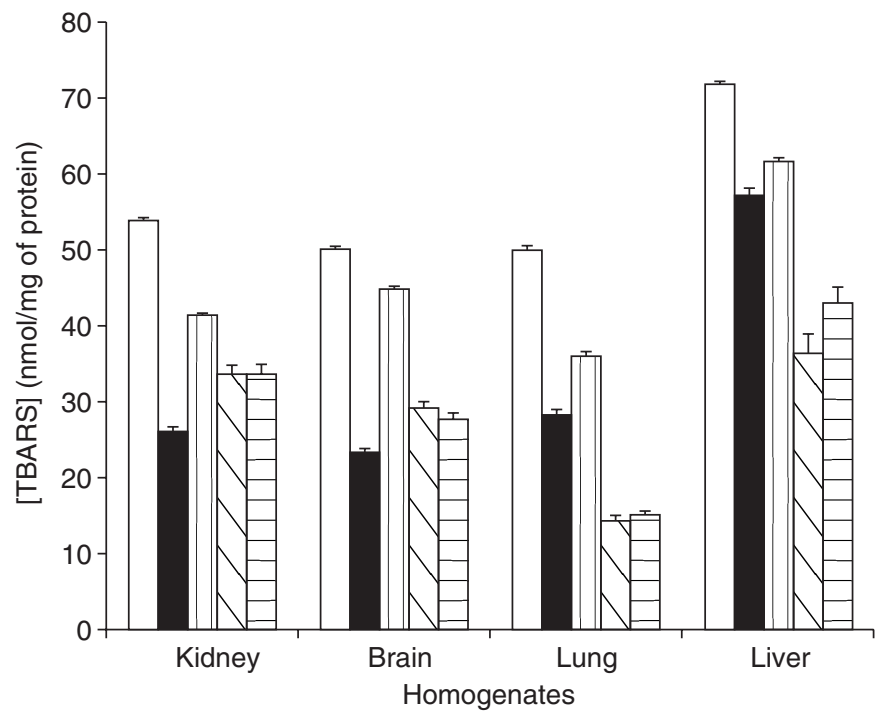

FIG. 2. Effect of different honey dilutions, vitamin E, and melatonin on TBARS content generated by NADH in the enzymatic TBA method assayed for 60 minutes at $37^{\circ} \mathrm{C}$ and homogenates at $3.3 \%(\mathrm{wt} / \mathrm{vol})$ in $50 \mathrm{~m} M$ phosphate buffer ( $\mathrm{pH}$ 7.4): homogenates in the presence of 2 $\mathrm{m} M$ NADH ( $\square$ ); homogenates in the presence of $2 \mathrm{~m} M \mathrm{NADH}$ and honey diluted 1:2(ם); homogenates in the presence of $2 \mathrm{mMNADH}$ and honey diluted 1:4 $(\mathbb{\nabla})$; homogenates in the presence of $2 \mathrm{mM}$ $\mathrm{NADH}$ and melatonin at $1 \mu M(\mathrm{E})$; homogenates in the presence of $2 \mathrm{~m} M \mathrm{NADH}$ and vitamin $\mathrm{E}$ at $1 \mu M$. 


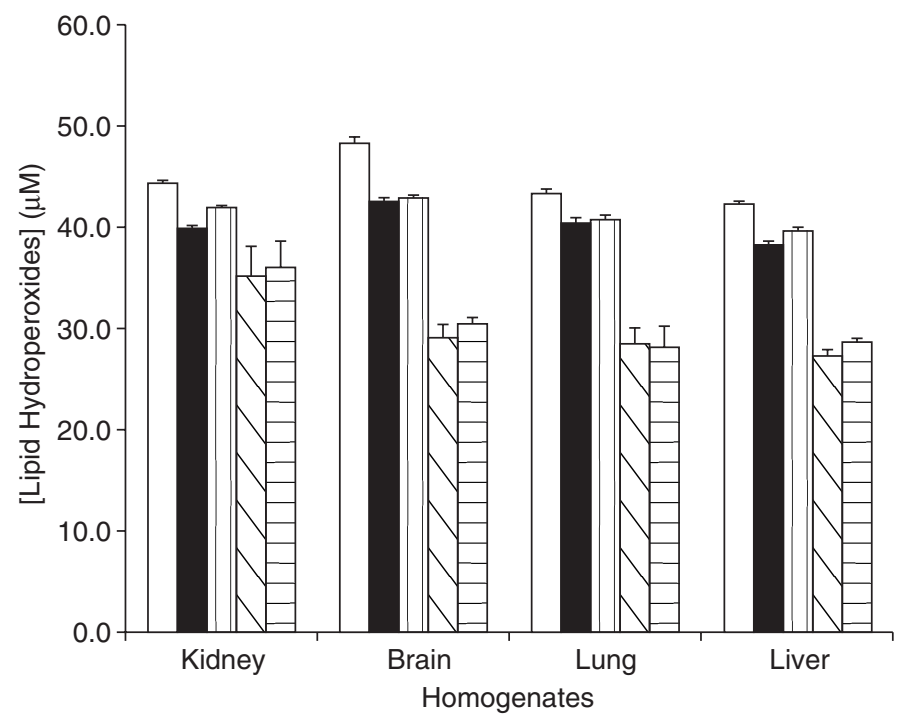

FIG. 3. Effect of different honey dilutions on lipid hydroperoxide concentration generated by Fenton's reagent $\mathbf{1}$ in the FOX method developed for 60 minutes at $37^{\circ} \mathrm{C}$ and homogenates at $40 \%$ (wt/vol) in HPLC-grade methanol: homogenates in the presence of Fenton's

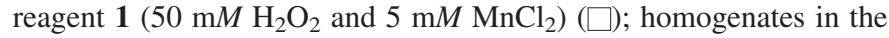
presence of Fenton's reagent $\mathbf{1}$ and honey diluted 1:2 (ם); homogenates in the presence of Fenton's reagent $\mathbf{1}$ and honey diluted 1:4 $(\mathbb{\nabla})$; homogenates in the presence of Fenton's reagent $\mathbf{1}$ and melatonin at $1 \mu M($ 目); homogenates in the presence of Fenton's reagent 1 and vitamin $\mathrm{E}$ at $1 \mu M$. reagent 1. Vitamin $\mathrm{E}$ and melatonin were more effective than honey samples in decreasing lipid hydroperoxide generation.

In Table 2 are presented the inhibition percentages found with all three methods that were used to measure the effect of honey on lipid peroxidation. It can be seen that inhibition percentages were higher for MDA production than for hydroperoxides. The highest inhibition in the nonenzymatic TBA method was observed in lung, and for the enzymatic TBA and FOX methods in brain. In general, for the three methods studied so far, melatonin and vitamin $\mathrm{E}$ have a higher antioxidant capacity than honey samples (Table 2).

\section{Measurement of AOA}

The honey AOA values show an antioxidant capacity at a concentration that is comparable to that of uric acid, a potent antioxidant found in living systems. ${ }^{28} \mathrm{AOA}$ values are presented in Table 3. It can be seen that the antioxidant capacity of honey at high concentration is equivalent to 0.62 $\mathrm{m} M$ uric acid, which is a relative high value because uric acid is used at $1 \mathrm{~m} M$ in this assay. Melatonin has a higher AOA value than the honey samples, but vitamin $\mathrm{E}$ has an AOA value similar to the lowest dilution of honey.

\section{DISCUSSION}

The lipid peroxidation process was induced by Fenton's reagent and NADH. Fenton's reagent is based on the reduction of $\mathrm{H}_{2} \mathrm{O}_{2}$ by an electron donated from metal ions to produce hydroxyl radical $\left(\mathrm{OH}^{*}\right)$. In most cases, iron is used

Table 2. Inhibition Percentages for Different Honey Dilutions and Comparison with Melatonin and Vitamin E Measured by TBA and FOX Methods

\begin{tabular}{|c|c|c|c|c|}
\hline \multirow[b]{2}{*}{ Sample } & \multirow[b]{2}{*}{ Organ } & \multicolumn{3}{|c|}{ Inhibition percentage (\%) by method } \\
\hline & & Nonenzymatic TBA & Enzymatic TBA & FOX \\
\hline \multirow{4}{*}{ Honey diluted $1: 2$} & Kidney & $24.9 \pm 0.2^{\mathrm{a}}$ & $51.5 \pm 0.6^{\mathrm{a}}$ & $10.3 \pm 0.1^{\mathrm{a}}$ \\
\hline & Brain & $25.3 \pm 0.1^{\mathrm{a}}$ & $53.7 \pm 0.4^{\mathrm{a}}$ & $11.9 \pm 0.5^{\mathrm{a}}$ \\
\hline & Lung & $31.2 \pm 0.5$ & $43.4 \pm 0.1$ & $8.2 \pm 0.2^{\mathrm{a}}$ \\
\hline & Liver & $14.2 \pm 0.3$ & $20.5 \pm 0.2$ & $9.6 \pm 0.4^{\mathrm{a}}$ \\
\hline \multirow{4}{*}{ Honey diluted $1: 4$} & Kidney & $19.6 \pm 0.3^{a}$ & $23.5 \pm 0.3$ & $5.5 \pm 0.6^{\mathrm{a}}$ \\
\hline & Brain & $18.5 \pm 0.2^{\mathrm{a}}$ & $10.5 \pm 0.2$ & $11.2 \pm 0.3$ \\
\hline & Lung & $5.5 \pm 0.1$ & $28.2 \pm 0.1$ & $6.9 \pm 0.1^{\mathrm{a}}$ \\
\hline & Liver & $8.5 \pm 0.1$ & $14.7 \pm 0.1$ & $6.3 \pm 0.1^{\mathrm{a}}$ \\
\hline \multirow{4}{*}{ Melatonin $(1 \mu M)$} & Kidney & $73.8 \pm 0.4^{\mathrm{a}}$ & $38.7 \pm 0.1$ & $19.5 \pm 0.2$ \\
\hline & Brain & $70.2 \pm 0.2^{\mathrm{a}}$ & $19.0 \pm 0.1$ & $40.7 \pm 0.2^{\mathrm{a}}$ \\
\hline & Lung & $69.2 \pm 0.1^{\mathrm{a}}$ & $72.1 \pm 0.5$ & $38.9 \pm 0.4^{\mathrm{a}}$ \\
\hline & Liver & $44.5 \pm 0.3$ & $49.7 \pm 0.4^{\mathrm{a}}$ & $40.0 \pm 0.4^{\mathrm{a}}$ \\
\hline \multirow[t]{4}{*}{ Vitamin E $(1 \mu M)$} & Kidney & $78.7 \pm 0.1$ & $38.8 \pm 0.3^{\mathrm{a}}$ & $24.7 \pm 0.5$ \\
\hline & Brain & $65.1 \pm 0.1^{\mathrm{a}}$ & $23.2 \pm 0.1$ & $40.5 \pm 0.6^{\mathrm{a}}$ \\
\hline & Lung & $67.1 \pm 0.1^{\mathrm{a}}$ & $70.8 \pm 0.1$ & $39.6 \pm 0.3^{a}$ \\
\hline & Liver & $46.4 \pm 0.2$ & $40.8 \pm 0.2^{\mathrm{a}}$ & $37.6 \pm 0.2$ \\
\hline
\end{tabular}

Data are mean \pm SE values $(n=3)$. Means within a sample sharing the letter ${ }^{(a)}$ are not significantly different by Newman-Keuls multiple comparison test $(P<.05)$. 
Table 3. AOA Values of Different Honey Dilutions and Comparison with Melatonin and Vitamin E

\begin{tabular}{ll}
\hline Dilution & $A O A(m M)$ \\
\hline Honey diluted & \\
$1: 2$ & $0.62 \pm 0.01^{\mathrm{a}}$ \\
$1: 4$ & $0.50 \pm 0.01$ \\
$1: 8$ & $0.30 \pm 0.02$ \\
Melatonin $(1 \mu M)$ & $0.79 \pm 0.01$ \\
Vitamin E $(1 \mu M)$ & $0.61 \pm 0.01^{\mathrm{a}}$ \\
\hline
\end{tabular}

Data are mean \pm SE values $(n=3)$. Means within a column sharing the same letter are not significantly different by Newman-Keuls multiple comparison test $(P<.05)$.

as a metal donor (Eq. 1), but in the case of the FOX method, manganese ions were used (Eq. 2), according to the followed reactions:

$$
\begin{gathered}
\mathrm{Fe}^{2+}+\underset{(\text { Fenton's reagent 2) }}{\mathrm{H}_{2} \mathrm{O}_{2} \rightarrow \mathrm{Fe}^{3+}+\mathrm{OH}^{-}+\mathrm{OH}^{\cdot}} \\
\mathrm{Mn}^{2+}+\underset{(\text { Fenton's reagent } \mathbf{1})}{\stackrel{\mathrm{H}_{2} \mathrm{O}_{2} \rightarrow \mathrm{Mn}^{3+}+\mathrm{OH}^{-}}{\left(\mathrm{OH}^{*}\right.}}
\end{gathered}
$$

$\mathrm{NADH}$ can induce lipid peroxidation because it forms part of enzymes such as lipoxygenases and cycloxygenases in archidonic acid metabolism that produce superoxide anion and hydroxyl radical. ${ }^{30}$ Both hydroxyl radical and superoxide anion are ROS, which are free radicals associated with oxygen atom or equivalents with a higher reactivity than molecular oxygen..$^{31,32}$ The hydroxyl radical has the capacity of reacting with many organic molecules to generate more free radicals. ${ }^{33}$ We demonstrated that our honey samples could inhibit NADH-dependent lipid peroxidation. Although we did not study which enzymes were inhibited, it has been reported by other authors that honey can act on enzymatic processes, for example, the browning of fruits and vegetables via the inhibition of polyphenol oxidase. ${ }^{34-36}$ Our results also show that honey is able to reduce the generation of lipid hydroperoxide. This is consistent with results reported by Sun et al. ${ }^{37}$ that propolis (a resinous material collected by bees from gum exudates of trees) could reduce levels of lipid hydroperoxides in vitamin E-deficient rats. In general, it has been reported that honey can prevent deteriorative oxidative reactions in foods, such as lipid oxidation. ${ }^{38}$

On one hand, vitamin $\mathrm{E}$ has been related to the protection against cardiovascular, Alzheimer's, and Parkinson's diseases, cancer, and immune infections. ${ }^{39}$ On the other hand, melatonin scavenges free radicals acting in an organism's protection against the aging process. ${ }^{40,41}$ In general, both vitamin $\mathrm{E}$ and melatonin have an antioxidant capacity higher than the honey samples in all methods used in this work. However, AOA values are particularly interesting. They showed that honey samples diluted 1:2 have similar values to those of vitamin $\mathrm{E}$ and melatonin (Table 3). Al- though we did not study honey enzymes, an explanation for this result could be a higher activation of honey catalase due to its dilution, and the concomitant reduction of hydrogen peroxide concentration necessary for the Fenton reaction. ${ }^{42}$ The values of honey AOA indicate a very good antioxidant activity when compared with organic fluids analyzed by this method such as urine $(0.17 \mathrm{mM})$, saliva $(0.84 \mathrm{mM})$, cerebrospinal fluid $(0.095 \mathrm{~m} M)$, and ocular aqueous humor $(0.061 \mathrm{mM})$. However, it is not as good as serum with an AOA value of $2.04 \mathrm{mM} .^{28}$

The honey antioxidant capacity found for lipid peroxidation and AOA is very similar to that of many fruits and vegetables measured by the oxygen radical absorbance capacity assay..$^{20}$ This honey antioxidant capacity can be related to the high concentration of phenolic compounds found in our honey samples $(125.17 \pm 0.05 \mathrm{mg} / \mathrm{L})$ in comparison with other types of honeys reported in the literature. ${ }^{17}$ Among these phenolic compounds we can find flavonoids, which are present in several types of honey and can have $\mathrm{AOA}^{43}$ and are derived from propolis ${ }^{44}$ and phenolic acids found in nectar. ${ }^{45,46}$ Phenolic compounds are very efficient scavengers of peroxyl radicals because of their molecular structures, which include an aromatic ring with hydroxyl groups containing mobile hydrogens. ${ }^{47}$ Moreover, the action of phenolic compounds can be related to their capacity to reduce or chelate divalent ions that catalyze lipid peroxidation. ${ }^{48}$ On the other hand, phenolic antioxidants (ArOH) may interrupt radical-initiated chain reactions by hydrogen atom transfer (Eq. 3) or by electron transfer (Eq. 4) with the formation of phenoxyl radical cation $\left(\mathrm{Ar}^{\cdot} \mathrm{OH}^{+}\right)$, which is rapidly and reversibly deprotonated, forming phenoxyl radical (ArO') (Eq. 5). ${ }^{49,50}$ These two mechanisms always occur in parallel but with different reactions rates. Although they give the same net result, the $\mathrm{H}$-atom transfer is preferable, since the radical cation, $\mathrm{Ar}^{\cdot} \mathrm{OH}^{+}$, formed by electron transfer may be mutagenic ${ }^{51}$ :

$$
\begin{aligned}
& \mathrm{ROO}^{\circ}+\mathrm{ArOH} \rightarrow \mathrm{ROOH}+\mathrm{ArO}{ }^{\circ} \\
& \text { (H-atom transfer) } \\
& \mathrm{ROO}^{*}+\mathrm{ArOH} \rightarrow \mathrm{ROO}^{-}+\mathrm{Ar}^{\cdot} \mathrm{OH}^{+} \\
& \text {(electron transfer) } \\
& \mathrm{Ar}^{\circ} \mathrm{OH}^{+}+\mathrm{H}_{2} \mathrm{O} \leftrightarrow \mathrm{ArO}^{\cdot}+\mathrm{H}_{3} \mathrm{O}^{+}
\end{aligned}
$$

A phenoxyl radical may also combine with peroxyl radical (ROO') (Eq. 6) forming nonradical products. ${ }^{51}$ Additionally, phenolic antioxidants may react with hydroxyl radicals (Eq. 7) or act as trapping agents of electrophilic genotoxic compounds such as benz[a]pyrene ${ }^{52}$ :

$$
\begin{aligned}
& \mathrm{ROO}^{`}+\mathrm{ArO}^{`} \rightarrow \text { nonradical products } \\
& \mathrm{HO}^{`}+\mathrm{ArOH} \rightarrow \mathrm{HOH}+\mathrm{ArO}^{`}
\end{aligned}
$$

Phenolic components in honey samples can act in any of the mechanisms mentioned previously. However, the levels of 
single phenolics or other compounds in honey are too low to have a major individual significance. Hence, the total antioxidant capacity of honey can be the result of the combined activity and interactions of a wide range of compounds, including phenolics, peptides, organic acids, enzymes, Maillard reaction products, and other minor components, but that is not clear at present. ${ }^{53}$

In conclusion, all honey samples tested showed an antioxidant capacity that depends on their concentration. This antioxidant capacity was lower than that of melatonin and vitamin $\mathrm{E}$ in the TBARS and FOX methods. However, in the case of AOA, honey AOA is comparable with that of uric acid and is dependent on its concentration as well. These results indicated that the honey antioxidant capacity is tissue, enzymatic, and method-sensitive. Therefore, further studies are necessary to clarify the antioxidant effect of honey.

\section{ACKNOWLEDGMENTS}

The authors wish to thank Dra. Natalia Dmitrieva for her critical reading of our manuscript.

\section{REFERENCES}

1. White JW: Composition of honey. In: Honey. A Comprehensive Survey (Crane E, ed.), London, Heinemann, 1979, pp. 157-207.

2. Salem SN: Honey regimen in gastrointestinal disorders. Bull Islamic Med 1981;1:358-362.

3. Haffejee IE, Moosa A: Honey in the treatment of infantile gastroenteritis. BMJ 1985;290:1886-1887.

4. Ladas SP, Haritos DN, Raptis SA: Honey may have a laxative effect on normal subjects because of incomplete fructose absorption. Am J Clin Nutr 1995;62:1212-1215.

5. Mobarok ATM, Al-Swayeh OA: Natural honey prevents ethanolinduced increased vascular permeability changes in the rat stomach. J Ethnopharmacol 1997;55:231-238.

6. Efem SC: Clinical observations on the wound healing properties of honey. Br J Surg 1988;75:679-681.

7. Subrahmanyam M: Topical application of honey in the treatment of burns. Br J Surg 1991;78:497-498.

8. Ali AT, Chowdhury MN, Al-Humayyd MS: Inhibitory effect of natural honey on Helicobacter pylori. Trop Gastroenterol 1991;12:73-77.

9. Allen KL, Molan PC, Reid GM: A survey of the anti-bacterial activity of some New Zealand honeys. J Pharm Pharmacol 1991;43:817-822.

10. Ali AT: Prevention of ethanol-induced gastric lesions in rats by honey, and its possible mechanism of action. Scand J Gastroenterol 1991;26:281-288.

11. Ali AT: Natural honey exerts its protective effect against ethanolinduced gastric lesions in rats by preventing depletion of glandular nonprotein sulfhydryls. Trop Gastroenterol 1995;16:18-26.

12. Halliwell B, Gutteridge JMC: Free Radicals in Biology and Medicine, $2^{\text {nd }}$ ed., Clarendon Press, Oxford, UK, 1989, pp. 51-57.

13. Halliwell B: How to characterize a biological antioxidant. Free Radic Res Commun 1990;9:1-32.

14. Larson RA: The antioxidants of higher plants. Phytochemistry 1988;27:969-978.
15. Hudson BJF: Food Antioxidants, Elsevier Applied Science, London, 1990.

16. Hall CA, Cuppet SL: Structure-activities of natural antioxidants. In: Antioxidant Methodology In Vivo and In Vitro Concepts (Aruoma OI, Cuppet SL, eds.), University of Illinois Press, Champaign, IL, 1997, pp. 2-29.

17. Al-Mamary M, Al-Meeri A, Al-Habori M: Antioxidant activities and total phenolics of different types of honey. Nutr Res 2002;22:1041-1047.

18. Antony SM, Rieck JR, Dawson PL: Effect of dry honey on oxidation in turkey breast meat. Poult Sci 2000;79:1846-1850.

19. Busserolles J, Gueux E, Rock E, Mazur A, Rayssiguier Y: Substituting honey for refined carbohydrates protects rats from hypertriglyceridemic and prooxidative effects of fructose. $\underline{J \text { Agric }}$ Food Chem 2002;50:5870-5877.

20. Gheldof N, Engeseth NJ: Antioxidant capacity of honey from various floral sources based on the determination of oxygen radical absorbance and inhibition of in vitro lipoprotein oxidation in human serum samples. J Agric Food Chem 2002;50:3050-3055.

21. Schramm DD, Karim M, Schrader HR, Holt RR, Cardetti M, Keen CL: Honey with high levels of antioxidants can provide protection to healthy human subjects. J Agric Food Chem 2003;51: 1500-1505.

22. Slater TF: Free radical mechanism in tissue injury. Biochem $J$ 1984;222:1-15.

23. Bernhard H, Phyllis G: Suggestions for pharmacological and nu-

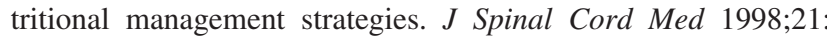
309-334.

24. Rauchova H, Ledvinkova J, Kalous M, Drahota Z: The effect of lipid peroxidation on the activity of various membrane-bound ATPases in rat kidney. Int J Biochem Cell Biol 1995; 27:251-255.

25. Tretter L, Adam-Vizi V: Early events in free radical-mediated damage of isolated nerve terminals: effects of peroxides on membrane potential and intracellular $\mathrm{Na}^{+}$and $\mathrm{Ca}^{2+}$ concentrations. $\underline{J}$ Neurochem 1996;66:2057-2066.

26. Jiang Z, Hunt J, Wolf S: Ferrous ion oxidation in the presence of xylenol orange for detection of lipid hydroperoxide in low density lipoprotein. Anal Biochem 1992;202:384-389.

27. Janero D: Malondialdehyde and thiobarbituric acid-reactivity as diagnostic indices of lipid peroxidation and peroxidative tissue injury. Free Radic Biol Med 1990;9:541-559.

28. Koracevic D, Koracevic G, Djordjevic V, Andrejevic S, Cosic V: Method for measurement of antioxidant activity in human fluids. J Clin Pathol 2001;54:356-361.

29. Lowry OH, Rosebrough NJ, Farr AL, Randall RJ: Protein measurement with the Folin phenol reagent. J Biol Chem 1951;193: 265-275.

30. Kukreja R, Kontos H, Hess M, Ellis E: PGH synthesis and lipoxygenase generated superoxide in presence of NADH and NADPH. Circ Res 1986;59:612-619.

31. Hogg N: Free radicals in disease. Semin Reprod Endocrinol 1988;16:241-248.

32. Toyokuni S: Reactive oxygen species-induced molecular damage and its application in pathology. Pathol Int 1999;49:91-102.

33. Gutteridge J, Halliwell B: Biologically relevant metal ion dependent hydroxyl radical generation: an update. FEBS Lett 1992;307: 108-112.

34. Oszmianski J, Lee CY: Inhibition of polyphenol oxidase activity and browning by honey. J Agric Food Chem 1990;38:18921895. 
35. McLellan MR, Kime RN, Lee CY, Long TM: Effect of honey as an antibrowning agent in light raisin processing. $\underline{J \text { Food Process }}$ Preserv 1995;19:1-8.

36. Chen L, Mehta A, Berenbaum M, Zangerl AR, Engeseth NJ: Honeys from different floral sources as inhibitors of enzymatic browning in fruit and vegetable homogenates. J Agric Food Chem 2000;48:4997-5000.

37. Sun F, Hayami S, Haruna S, Ogiri Y, Tanaka K, Yamada Y, Ikeda K, Yamada H, Sugimoto H, Kawai N, Kojo S: In vivo antioxidative activity of propolis evaluated by the interaction with vitamins $\mathrm{C}$ and $\mathrm{E}$ and the level of lipid hydroperoxides in rats. $\underline{J}$ Agric Food Chem 2000;48:1462-1465.

38. McKibben J, Engeseth NJ: Honey as a protective agent against lipid oxidation in ground turkey. J Agric Food Chem 2002;50:592-595.

39. Pryor W: Vitamin E and heart disease: basic science to clinical intervention trials. Free Radic Biol Med 2000;28:141-164.

40. Poeggler B, Reiter R, Tan D, Chen L, Manchester L, Guerrero J: Melatonin hydroxyl radical-mediated oxidative damage and aging: a hypothesis. $\underline{J}$ Pineal Res $1993 ; 14: 151-168$.

41. Reiter R, Guerrero J, Garcia J, Acuña D: Reactive oxygen intermediates, molecular damage, and aging. Ann N Y Acad Sci $1998 ; 854: 410-424$.

42. Weston, RJ: The contribution of catalase and other natural products to the antibacterial activity of honey: a review. Food Chem 2000;71:235-239.

43. Pietta P, Simonetti P, Mauri P: Antioxidant activity of selected medicinal plants. J Agric Food Chem 1998;46:4123-4127.

44. Marucci MC: Propolis: chemical composition, biological properties and therapeutic activity. Apidologie 1995;26:89-99.
45. Gil MI, Ferreres F, Ortiz A, Subra E, Thomas-Barverian FA: Plant phenolic metabolites and floral origin of rosemary honey. $\underline{J \text { Agric }}$ Food Chem 1995;43:2833-2838.

46. Ferreres F, Andrade P, Gil MI, Thomas-Barberian FA: Floral nectar phenolics as biochemical markers for the botanical origin of heather honey. Z Lebensm Unters Forsch 1996;202:40-44.

47. Aruoma OI: Nutrition and health aspects of free radicals and antioxidants. Food Chem Toxicol 1994;32:671-683.

48. Gazzani G, Papetti A, Daglia M, Berte F, Gregotti C: Protective activity of water soluble components of some common diet vegetables on rat liver microsomes and the effect of thermal treatment. J Agric Food Chem 1998;46:4123-4127.

49. Simic MG: Antioxidant compounds: an overview. In: Oxidative Damage and Repair (Davies KJA, ed.), Pergamon Press, New York, 1992, pp. 47-59.

50. Wright JS, Johnson ER, DiLabio GA: Predicting the activity of phenolic antioxidants: theorical method, analysis of substituent effects, and application to major families of antioxidants. $\underline{\mathrm{Jm}}$ Chem Soc 2001;123:1173-1181.

51. Barclay LRC, Edwards CE, Vinqvist MR: Media effects on antioxidant activities of phenols and catechols. 1999;121:6226-6231.

52. Wattenberg LW, Coccia JB, Lam LKT: Inhibitory effects of $\beta$ carotene, $\alpha$-tocopherol and five naturally occurring antioxidants on initiation of hepatocarcinogenesis by 2 -amino-3-methylimidazo[4,5-f]quinoline in the rat. Cancer Res 1980;40:2820-2823.

53. Gheldof N, Wang X, Engeseth N: Identification and quantification of antioxidants components of honeys from various floral sources. J Agric Food Chem 2002;50:5870-5877. 